\title{
Breakfast: A Crucial Meal for Adolescents' Cognitive Performance According to Their Nutritional Status. The Cogni-Action Project
}

\author{
Humberto Peña-Jorquera ${ }^{1}$, Valentina Campos-Núñez ${ }^{1}$, Kabir P. Sadarangani ${ }^{2,3}$ (), Gerson Ferrari ${ }^{4}$ (D) \\ Carlos Jorquera-Aguilera ${ }^{5}$ and Carlos Cristi-Montero ${ }^{1, * \text { (D) }}$ \\ 1 IRyS Group, Physical Education School, Pontificia Universidad Católica de Valparaíso, \\ Viña del Mar 2530388, Chile; humberto.apj@gmail.com (H.P.-J.); camposnunezvalentina@gmail.com (V.C.-N.) \\ 2 Universidad Autónoma de Chile, Providencia 7500912,Chile; kabir.sadarangani@gmail.com \\ 3 Escuela de Kinesiología, Facultad de Salud y Odontología, Universidad Diego Portales, Santiago 8370057, Chile \\ 4 Escuela de Ciencias de la Actividad Física, el Deporte y la Salud, Universidad de Santiago de Chile (USACH), \\ Santiago 7500618, Chile; gersonferrari08@yahoo.com.br \\ 5 Escuela de Nutrición y Dietética, Facultad de Ciencias, Universidad Mayor, Santiago 8580745, Chile; \\ carlos.jorquera@mayor.cl \\ * Correspondence: carlos.cristi.montero@gmail.com
}

\section{check for}

updates

Citation: Peña-Jorquera, $\mathrm{H}$; Campos-Núñez, V.; Sadarangani, K.P.; Ferrari, G.; Jorquera-Aguilera, C.; Cristi-Montero, C. Breakfast: A Crucial Meal for Adolescents Cognitive Performance According to Their Nutritional Status. The Cogni-Action Project. Nutrients 2021, 13, 1320. https://doi.org/10.3390/ nu13041320

Academic Editor: Dawn K. Wilson

Received: 19 February 2021

Accepted: 30 March 2021

Published: 16 April 2021

Publisher's Note: MDPI stays neutral with regard to jurisdictional claims in published maps and institutional affiliations.

Copyright: (c) 2021 by the authors. Licensee MDPI, Basel, Switzerland. This article is an open access article distributed under the terms and conditions of the Creative Commons Attribution (CC BY) license (https:// creativecommons.org/licenses/by/ $4.0 /)$
Abstract: This study aimed to determine whether pupils who have breakfast just before a cognitive demand, do not regularly skip breakfast, and consume a high-quality breakfast present higher cognitive performance than those who do not; furthermore, to establish differences according to their nutritional status. In this study, 1181 Chilean adolescents aged 10-14 years participated. A global cognitive score was computed through eight tasks, and the body mass index z-score (BMIz) was calculated using a growth reference for school-aged adolescents. The characteristics of breakfast were self-reported. Analyses of covariance were performed to determine differences in cognitive performance according to BMIz groups adjusted to sex, peak height velocity, physical fitness global score, and their schools. A positive association was found in adolescents' cognitive performance when they had breakfast just before cognitive tasks, did not regularly skip breakfast, presented at least two breakfast quality components, and included dairy products. No significant differences were found between breakfast components, including cereal/bread and fruits/fruit juice. Finally, pupils who were overweight/obese who declared that they skipped breakfast regularly presented a lower cognitive performance than their normal-BMIz peers. These findings suggest that adolescents who have breakfast just prior to a cognitive demand and regularly have a high quality breakfast have better cognitive performance than those who do not. Educative nutritional strategies should be prioritized, especially in "breakfast skippers" adolescents living with overweight/obesity.

Keywords: breakfast; cognition; children; obesity; meals; nutrition; breakfast skippers

\section{Background}

Complete and balanced nutrition is essential to maintain health in optimal conditions and avoid health risks throughout the entire life cycle. However, during the development stage and, particularly, during early adolescence, nutrition becomes essential due to its influences on brain maturation and future health indicators [1,2]. It is well-known that, in childhood and adolescence, food habits are strongly influenced by family, guardians, culture, and socio-economic context, which impact meals' frequency and quality [3,4]. Therefore, adolescents' eating patterns play a fundamental role in their global health, behavior, and cognitive functioning, which are relevant outcomes at the scholar age [2].

Breakfast has been recognized as an essential meal associated with high intake of proteins, vitamins, and minerals, and raised glucose blood concentration [5-7]. Moreover, a high-quality breakfast has been related to a lower risk of obesity [4]. Thereby, both 
a nutrient deficit and obesity have been linked to lower cognitive functioning during childhood [8-10]. Having a regular breakfast and improving its quality could enhance children's cognitive performance $[11,12]$ through enhanced episodic and visual memory, attention, and other cognitive skills [13-15]. For instance, a large-scale and empirical study of Chinese elementary and middle school students' data $(N=56,238$ and $N=91,543$, respectively) concluded that eating breakfast every day had a significant effect on academic quality (a proxy variable for cognitive development) [12].

However, despite the documented benefits of breakfast consumption, skipping breakfast is more common than specialists expect. Depending on the definition of skipping breakfast and the studied age group, the prevalence ranges from $10 \%$ to $74.7 \%$ in children and adolescents $[16,17]$. Notably, the frequency of skipping breakfast increases in adolescents $[16,18]$ and is higher in girls $[16,19]$, and "breakfast skippers" tend to consume more fast food, leading to increased weight gain from adolescence to adulthood [20]. Similarly, adolescents with an excess of adiposity have decreased cognitive functioning $[8,9]$.

The fundamentals underlying the interactions among obesity with brain health and cognition involve neuroelectric indicators [21], the energy demand of the brain [22], lowgrade inflammation and hormonal production alteration [22], grey and white brain matter volumes [23], and phagocytosis of synapses by microglia [24], among others. This complex and detrimental environment converges on a reduction in brain activity, affecting cognitive performance. However, currently, the literature is inconsistent regarding how nutritional status influences cognitive functioning in childhood [25]; thus, a challenge in this area is establishing the role of breakfast on this relationship (obesity/cognition) [4].

This study seeks to elucidate the relationship between breakfast and cognition according to the adolescents' nutritional status, covering a geographical gap. Most studies on this subject come from developed countries with more favorable economic and social contexts. Therefore, based on a large sample of Chilean pupils, the primary study aim was to determine whether those who have breakfast just before a complete cognitive battery, do not regularly skip breakfast, and consume a high-quality breakfast present higher cognitive performance than those who do not. Moreover, the purpose was to establish differences according to their nutritional status.

\section{Materials and Methods}

\subsection{Study Design}

This study is part of the Cogni-Action Project, which seeks to establish the association among physical activity, sedentary behavior, and physical fitness with brain structure and function, cognitive performance, and academic achievement in Chilean adolescents [26]. More information on the Cogni-Action project is provided elsewhere [26]. This project was retrospectively registered (8 July 2020) in the Research Registry (ID: researchregistry5791). The cross-sectional project was carried out from March 2017 to October 2019, where 10-14 years-old (5th to 8th grades) adolescents were recruited from the public, voucher, and private schools in Valparaiso, Chile.

\subsection{Study Population}

Total sample size and power calculations were based on pupils' total enrolment from 5 th to 8 th grades in the Valparaiso region indicated by the Chilean Ministry of Education in the year 2016 (universe $n=951,962$ ). It was based on a proportion and considered to have a heterogeneity of $50 \%$, confidence interval of $99 \%, 5 \%$ error range, and a dropout of $20 \%$. Thus, a total of 797 participants were necessary to have a representative sample. The general inclusion criteria were a girls and boys from 5th to 8th grades. A total of 1586 pupils were involved in this project. For the present study, 1181 pupils were included after applying the exclusion criteria (a) being out of the age range, and (b) not participating in the cognitive evaluation. 


\subsection{Measurements}

Measurements took place in schools between 9:00 and 15:00 through two sessions of four hours each, separated by eight days apart. In the early hours of the morning (session one), a complete cognitive battery was applied, and after that, anthropometric measurements and nutritional questionnaires were evaluated. In session two, physical fitness was assessed. Trained instructors from our research team guided all evaluations, and pupils had a brief familiarization trial before each test.

\subsubsection{Cognitive Performance}

Adolescents' cognitive performance was assessed through the NeuroCognitive Performance Test (NCPT) from Lumos Labs, Inc., San Francisco, CA, USA. The NCPT is a brief, modular, and online neuropsychological assessment platform [27]. It was applied in schoolrooms, in groups of 25 pupils, each with a laptop connected to the internet. The entire session lasted around one hour, which consisted of a brief explanation about the session's aim, a demonstration, practice before each task, and the execution.

The NCPT is made up of 17 subtasks that each researcher can combine to build custom test batteries. In this sense, we selected eight tasks to evaluate several cognitive skills, such as working memory, processing speed, problem-solving, selective and divided attention, fluid and logical reasoning, and cognitive flexibility (details in Solis-Urra et al., 2019) [26] A global cognitive performance score was computed; thus, each test was scaled following a normal inverse transformation of the percentile rank 25. These procedures benefitted from having scaled scores derived on the same normal distribution with a mean of 100 and a standard deviation of 15 . Therefore, a mean of the eight tasks was calculated and used as an indicator of global cognitive performance.

\subsubsection{Nutritional Status}

Pupils wore shorts, a t-shirt, and no trainers when their body weight $(\mathrm{kg})$ and height $(\mathrm{cm})$ were measured. A digital balance was used for measuring weight with precision between $0.1 \mathrm{~kg}$ and $150 \mathrm{~kg}$ (OMROM, HN-289-LA, Kyoto, Japan), while height was measured using a portable stadiometer (SECA, model 213, GmbH Co., Hamburg, Germany). A nutritional status indicator, the body mass index z-score (BMIz), was determined using the World Health Organization (WHO) 2007 growth reference for children and adolescents adjusted to their age and sex [28]. This indicator considers that a child's BMIz cannot be fixed as in adults because their fat levels changes over time (age) and mature (growth patterns differ between boys and girls). According to WHO recommendations for children and adolescents ranged 5-19 years, the thresholds were as follow: thinness: $<-2 \mathrm{SD}$, normal: between $>-2 \mathrm{SD}$ to $<+1 \mathrm{SD}$, overweight: between $+1 \mathrm{SD}$ and $<+2 \mathrm{SD}$, and obesity: $>+2 \mathrm{SD}$. In this study, two categories were computed: "normal-BMIz" and adolescents with "overweight/obesity". Only three cases were $<-2 \mathrm{SD}$ and were excluded from the analysis.

\subsubsection{Breakfast Information}

Several nutritional questions and a validated questionnaire (self-reported) were applied during the first evaluation session. Just before pupils took their cognitive performance test, we asked whether they had breakfast (yes/no). Based on a question from the Mediterranean Diet Quality Index (KIDMED) for children and adolescents [29], we asked whether they skipped breakfast regularly (yes/no). Additionally, a breakfast quality score was computed according to the EndKid Study criteria [30], assessing for (yes/no) a portion of (a) cereals/bread, (b) dairy (e.g., milk, yoghurt, cheese), and (c) fruits or natural juice without sugar in their breakfast. Thus, 1 point was awarded for each of the three food groups, resulting in a possible score of 0 to 3 .

\subsubsection{Covariates}

Sex, peak high velocity (PHV), physical fitness, and schools were used as covariates in all models. The BMIz-score was added to the model when the analysis involved all 
adolescents without splitting them by nutritional status. Sex, age, and maturation are personal modulators of cognitive development [31]. Thus, PHV was considered a maturity status indicator computed from age and height following Moore's equations [32]. The PHV age was subtracted from the chronological age, and the difference in years was defined as the value of maturity offset, permitting for comparisons of somatic maturity between boys and girls. BMIz and physical fitness are critical behavioral moderators of adolescents' cognitive performance [26]. BMIz measurement was described previously. A global score of physical fitness was computed adding z-scores based on sex and age as a normalized score of muscular, cardiorespiratory, and speed-agility fitness. Overall, physical fitness was evaluated by the ALPHA-fitness test battery [33]. This is a valid, reliable, feasible, and safe field-based fitness test in children and adolescents that permits the assessment and monitoring of many pupils simultaneously. All tests were performed in sports fields or an indoor gym during the morning, and pupils wore appropriate sportswear. Adolescents practised each test previously guided by a trainer and then started when they felt confident. Finally, school was included as a covariate due to the association between cognitive performance, socio-economic background, physical fitness, and academic performance [34,35]. In children from Latin-America, cognitive and academic achievements seem to be more closely related to school characteristics (i.e., economic, social, and cultural status) than variables associated with socioeconomic status (personal/familiar), which would explain to a great extent the outcome of the present study (cognitive performance) [36].

\subsubsection{Statistical Analyses}

Descriptive and comparative analyses are presented as means (and their standard deviation) and frequency (and their percentage). Differences between BMIz groups in continuous and factor variables were tested using the Student's $t$-test for equal variances and the Chi-square test, respectively (Table 1). Parametric analyses were carried out according to the central limit theorem, which indicates that, when the sample size is over 500, parametric methods are safe even though skewed data are present [37]. However, simultaneously, Q-Q visual analysis was performed, and Leven's test range from $p=390$ to $p=0.740$. One-way analyses of covariance (ANCOVA) were performed to assess the mean differences in adolescents' cognitive performance (adjusted by sex, PHV, BMIz, and schools) and according to BMIz groups (adjusted by sex, PHV, and schools). A Tukey post-hoc pairwise comparison was conducted to establish differences in the marginal estimated means in each pair of groups. Additionally, two effect size estimations were used, the first $\left(\eta^{2} p\right)$ for the global analysis and the second (Cohen's d) for comparisons between groups. The $\eta^{2} p$ was interpreted as small at 0.01 , medium at 0.06 , and large at 0.14 ; while the Cohen's $d$ was interpreted as no effect $(<0.2)$, small effect $(0.2<0.5)$, medium effect $(0.5<0.8)$, and large effect $(\geq 0.8)$ [38]. The significance level was set at $p<0.05$. All statistical analyses were performed with the free and open statistical software JAMOVI [Computer Software] (version 1.6.7.0, Sydney, Australia).

Table 1. Adolescents' characteristics according to nutritional status.

\begin{tabular}{ccccc}
\hline Variables & $\begin{array}{c}\text { Overall } \\
(\boldsymbol{n}=\mathbf{1 1 8 1})\end{array}$ & $\begin{array}{c}\text { Normal BMI } \\
(\boldsymbol{n}=\mathbf{5 6 3})\end{array}$ & $\begin{array}{c}\text { OW/OB BMI } \\
(\boldsymbol{n}=\mathbf{6 1 8})\end{array}$ & $\boldsymbol{p}$-Value \\
\hline Age (years) & $11.7 \pm 1.06$ & $11.8 \pm 1.1$ & $11.6 \pm 1.1$ & $<0.001$ \\
Sex (girls/boys) & $580 / 601$ & $280 / 283$ & $300 / 318$ & 0.683 \\
Weight (kg) & $50.3 \pm 11.9$ & $42.9 \pm 7.6$ & $57.1 \pm 11.0$ & $<0.001$ \\
Height (cm) & $152.4 \pm 9.2$ & $151.8 \pm 9.6$ & $153.1 \pm 8.8$ & $<0.001$ \\
BMIz-score & $1.04 \pm 1.07$ & $0.13 \pm 0.6$ & $99.6 \pm 0.6$ & $<.9$ \\
Cognitive test score & $100.0 \pm 8.8$ & $100.5 \pm 8.8$ & & 0.001 \\
Having breakfast & & & $364(35.4 \%)$ & \\
before a cognitive test & & $329(32.0 \%)$ & $183(17.9 \%)$ & \\
Yes & $693(67.5 \%)$ & $151(14.7 \%)$ & \\
No & $334(32.5 \%)$ & &
\end{tabular}


Table 1. Cont.

\begin{tabular}{|c|c|c|c|c|}
\hline Variables & $\begin{array}{c}\text { Overall } \\
(n=1181)\end{array}$ & $\begin{array}{l}\text { Normal BMI } \\
\quad(n=563)\end{array}$ & $\begin{array}{c}\text { OW/OB BMI } \\
(n=618)\end{array}$ & $p$-Value \\
\hline $\begin{array}{l}\text { Skipping breakfast } \\
\text { regularly }\end{array}$ & & & & $<0.001$ \\
\hline Yes & $247(24.0 \%)$ & $96(9.5 \%)$ & $151(14.6 \%)$ & \\
\hline No & $782(76.0 \%)$ & $399(38.7 \%)$ & $383(37.2 \%)$ & \\
\hline Breakfast quality score & & & & 0.570 \\
\hline 0 point & $171(17.2 \%)$ & $76(7.6 \%)$ & $95(9.6 \%)$ & \\
\hline 1 point & $319(32.1 \%)$ & $159(16.0 \%)$ & $160(16.1 \%)$ & \\
\hline 2 points & $372(37.4 \%)$ & $176(17.8 \%)$ & $196(19.7 \%)$ & \\
\hline 3 points & $132(13.3 \%)$ & $68(6.8 \%)$ & $64(6.4 \%)$ & \\
\hline $\begin{array}{l}\text { Fruits/natural juice } \\
\text { without sugar }\end{array}$ & & & & 0.382 \\
\hline Yes & $199(19.9 \%)$ & $90(9.0 \%)$ & $109(10.9 \%)$ & \\
\hline No & $801(80.1 \%)$ & $390(39.0 \%)$ & $411(41.1 \%)$ & \\
\hline $\begin{array}{c}\text { Cereals/bread in the } \\
\text { breakfast }\end{array}$ & & & & 0.506 \\
\hline Yes & $726(69.7 \%)$ & $354(34.0 \%)$ & $372(35.7 \%)$ & \\
\hline No & $316(30.3 \%)$ & $147(14.1 \%)$ & $169(16.2 \%)$ & \\
\hline Dairy in the breakfast & & & & 0.188 \\
\hline Yes & $622(60.2 \%)$ & $309(30.0 \%)$ & $313(30.3 \%)$ & \\
\hline No & $411(39.8 \%)$ & $187(18.1 \%)$ & $224(21.6 \%)$ & \\
\hline
\end{tabular}

Values are presented as means and standard deviation $( \pm)$ or frequencies and percentages $(\%), t$-student or Chi-square tests for comparisons between groups $(p<0.05)$; BMI: body mass index; OW: overweight; OB; obesity.

\section{Results}

Table 1 shows the participant characteristics of the study. The sample consisted of $50.9 \%$ boys, and $52.3 \%$ of pupils presented overweight or obesity. Moreover, $24 \%$ of adolescents declared themselves "breakfast skippers". Significant differences were found between BMIz groups in several personal characteristics and the primary outcomes, such as BMIz and cognitive performance. There were no significant differences in most breakfast variables, only in the skipping breakfast regularly item.

Figure 1 shows the results of the three main breakfast variables associated with cognitive performance in all adolescents (Figure $1 \mathrm{~A}-\mathrm{C}$ ) and according to their nutritional status (Figure 1D-F). All six general models were statistically significant $(p<0.001)$. Comparative analyses showed that (A) adolescents who had breakfast just before a cognitive test presented significant differences in comparison to those who did not $(p=0.020$; Cohen's $\mathrm{d}=0.18)$; (B) pupils who skipped breakfast regularly underperformed in the cognitive test $(p=0.001$; Cohen's $d=0.27)$; and (C) higher cognitive performance was observed when at least two components were included in breakfast ( 0 vs. 2 components: $p=0.001$; Cohen's d $=0.30$ ). Analyses according to BMIz groups showed that $(D)$ no differences were found between groups regarding who had breakfast just before a cognitive test or not; (E) a significant and negative difference was observed in adolescents with overweight/obesity who skipped breakfast regularly ( $p=0.002$; Cohen's $\mathrm{d}=0.38)$; and $(\mathrm{F})$ regarding breakfast quality, differences were observed in normal-BMIz pupils ( 0 vs. 2 components; $p=0.053$; Cohen's $\mathrm{d}=0.45$ ) and the same group (normal-BMIz) compared to the overweight/obesity group ( 0 vs. 2 components; $p=0.050$; Cohen's $\mathrm{d}=0.45$ ). 
A. Have breakfast before a cognitive test

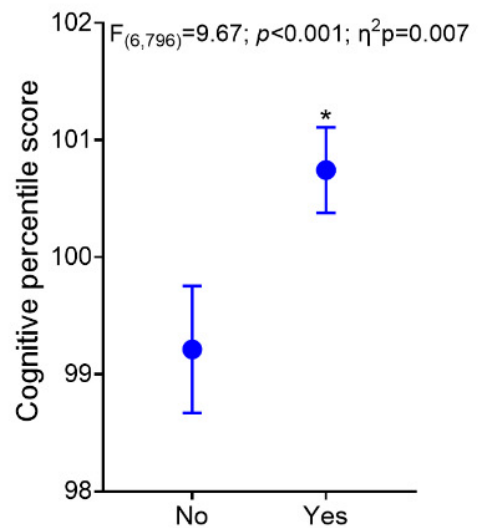

D. Have breakfast before a cognitive test by BMIz

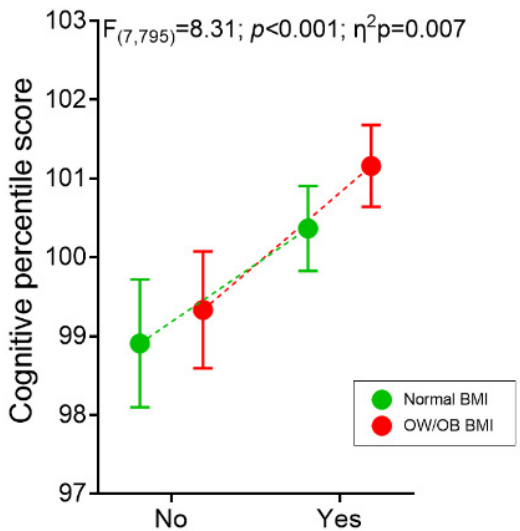

B. Skip breakfast regularly

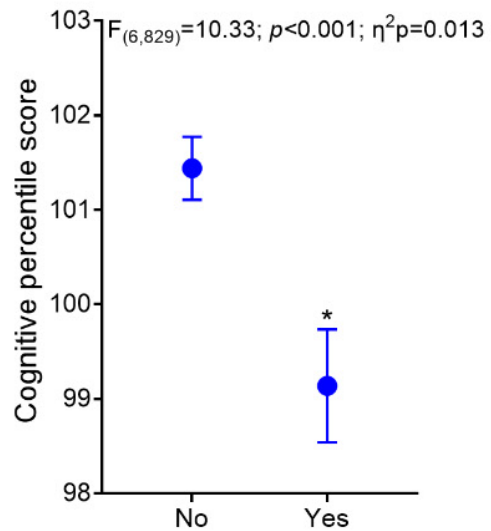

E. Skip breakfast regularly by BMIz

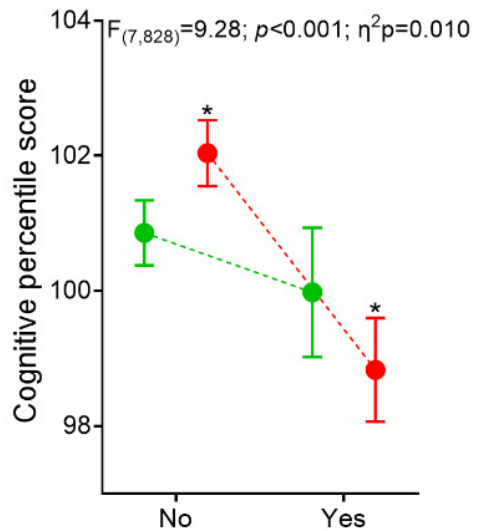

C. Breakfast quality score

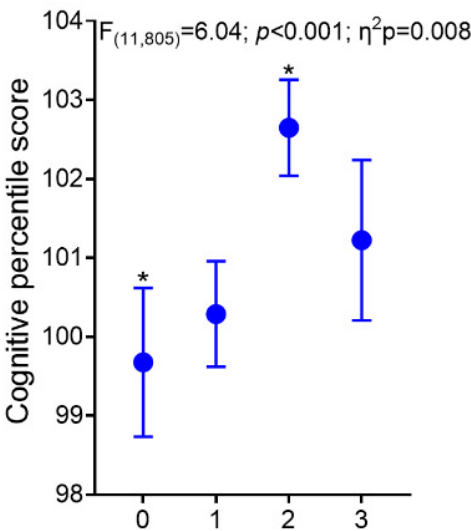

F. Breakfast quality score by BMIz

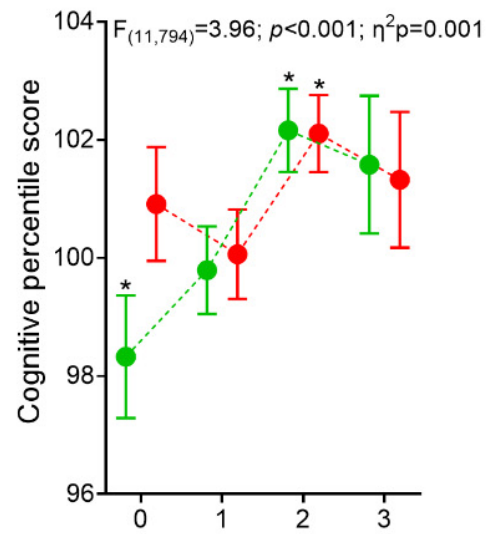

Figure 1. Differences in adolescents' cognitive performance according to breakfast consumption and quality. Models in figures (A-C) were adjusted to sex, peak high velocity, physical fitness, schools, and body mass index z-score. In contrast, models in figures (D-F) were adjusted to sex, peak high velocity, fitness, and schools. * Significative mean differences between groups. BMI: body mass index; OW: overweight; OB; obesity.

Figure 2 shows the three main breakfast quality components associated with all pupils' cognitive performance (Figure 2A-C) and according to their nutritional status (Figure 2D-F). All six general models were statistically significant $(p<0.001)$. Overall, no differences were found in cereal/bread and fruits/natural juice components between groups (Figure 2A,C). However, adolescents who consumed dairy for breakfast were significantly different from those that did not $(p=0.004$; Cohen's $\mathrm{d}=0.21)$ (Figure 2B). No differences in breakfast quality were found in cereal/bread and fruits/natural juice according to BMIz groups (Figure 2D,F). However, differences were observed in the normalBMIz pupils ( 0 vs. 2 components; $p=0.045$; Cohen's $\mathrm{d}=0.46$ ) and the same group (normalBMIz) compared to the overweight/obesity group ( 0 vs. 2 components; $p=0.047$; Cohen's $\mathrm{d}=0.45)$. 


\section{A. Cereal/bread in the breakfast}

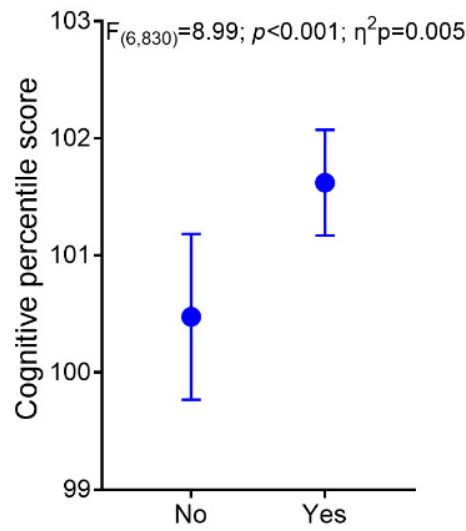

D. Cereal/bread in the breakfast by BMIz

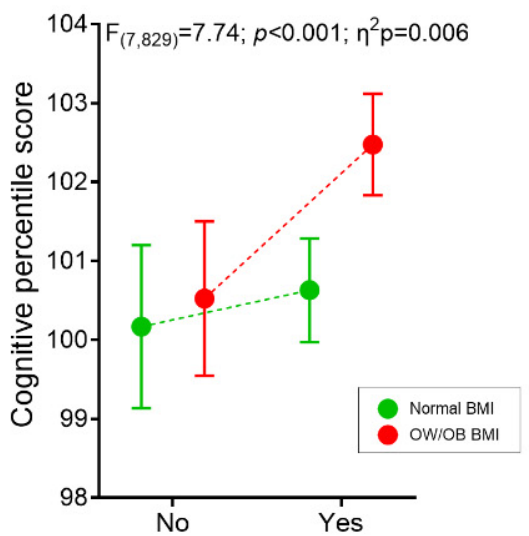

\section{B. Dairy in the breakfast}

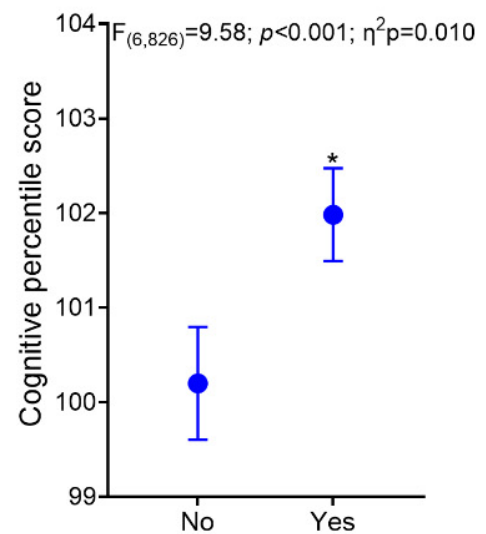

E. Dairy in the breakfast by BMIz

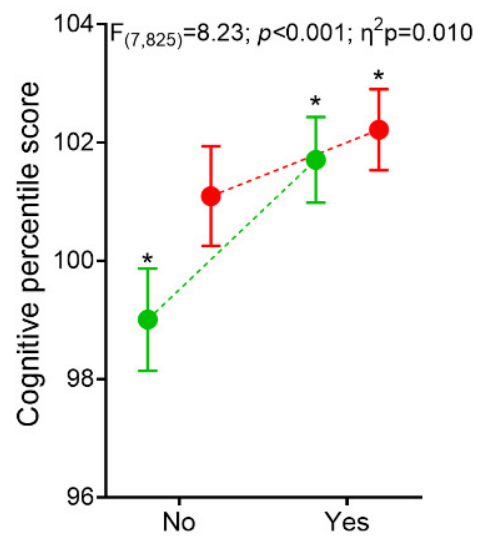

\section{Fruits/Natural juice without sugar}

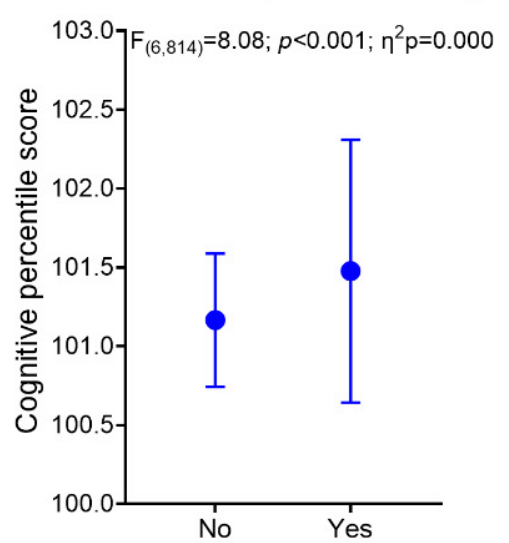

F. Fruits/Natural juice without sugar by BMlz

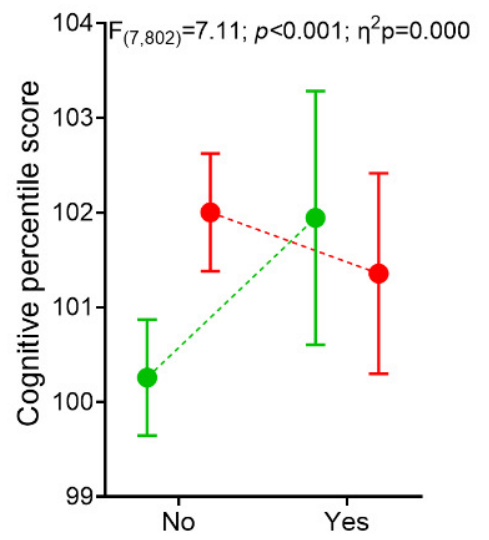

Figure 2. Differences in the adolescents' cognitive performance according to the three quality breakfast components analyzed. Models in figures (A-C) were adjusted to sex, peak high velocity, fitness, schools, and body mass index z-score, whereas models in figures (D-F) were adjusted to sex, peak high velocity, fitness, and schools. ${ }^{*}$ Significative mean differences between groups. BMI: body mass index; OW: overweight; OB: obesity.

\section{Discussion}

This study aimed to determine whether adolescents who eat breakfast just before a complete cognitive evaluation, do not regularly skip breakfast, and consume a highquality breakfast present a higher cognitive performance; furthermore, to establish possible differences according to their nutritional status. The main findings were that pupils who had breakfast before a cognitive evaluation, have breakfast regularly, and consume at least two breakfast quality components seem to have greater cognitive performance than those who do not. In this line, higher cognitive performance was present in adolescents who included dairy products. Regarding their nutritional status, cognitive performance was lower in pupils with overweight/obesity and who regularly skipped breakfast compared to those who did not.

Overall, to improve the understanding of how having breakfast influences the brain and, in turn, cognitive performance, it is necessary to consider some relevant factors related to skipping this meal. In this sense, previous studies have shown some mixed and equivocal findings according to the type of breakfast consumed, participants' characteristics, and the study's methodological features. Some of these factors are (a) variable analyzed (e.g., energy balance, health parameter, cognitive performance); (b) study population (e.g., athletes, elderly, schoolchildren, socio-economic background); (c) effect of skipping breakfast (as a result of lack of habit) vs. planned intermittent fasting (e.g., skipping breakfast every other day); (d) age, intelligence quotient, physical fitness level, and baseline metabolic 
characteristics; (e) specificity of breakfast composition; (f) prolonged overnight fast (e.g., last meal); (g) type of participant's diet (e.g., ketogenic diet); and (h) lack of experimental and well-designed randomized controled trials [39-41]. This complex net of factors makes it challenging to establish the real effect and association of breakfast on brain health and compare results.

\subsection{Skipping Breakfast and Cognitive Performance}

In our study, which, methodologically, could be deemed quasi-experimental and ecological research, adolescents having breakfast just before a cognitive demand showed enhanced cognitive performance compared to those who did not. Furthermore, no evidence of differences according to their nutritional status was established. In this sense, several studies showed that skipping breakfast impacts the children and adolescents' cognitive and academic achievement, negatively impairing their problem-solving ability, attention, and episodic memory in the morning $[12,13,42]$. However, this detrimental cognitive effect was not observed in children (8-10 years) who regularly consumed breakfast and skipped it once [43]. In the case of children with obesity and "breakfast skippers", it has been established that they present some metabolic alterations (e.g., leptin gene mutation, reduction of carbohydrate utilisation) associated with a reduction in attention [15] and verbal, non-verbal, and short-term memory [44]. It is essential to highlight that while skipping breakfast has been related to a higher risk of obesity, the current evidence is ambiguous [40].

Despite all these relevant aspects, it is also crucial to consider the adolescents' social context and familial support, because most "breakfast skippers" have unfavorable socioeconomic backgrounds $[12,45]$. Social factors have been related to worse food quality and physical inactivity, among others, influencing a higher rate of overweight/obesity [46]. This vicious circle, which negatively affects cognition and academic achievement, seems to improve if children and adolescents are educated and receive subsidized breakfast at school [47]. More studies are necessary to have a clear relationship between skipping breakfast, obesity, and cognitive performance.

\subsection{Breakfast Quality and Cognitive Performance}

\subsubsection{Cereals and Fruits}

It is well known that a high-quality breakfast is a great source of amino acids, vitamins, minerals, antioxidants, and fiber, which positively impacts children's global health and cognition [5-7]. In this way, evidence indicates that breakfast composition may affect behavior, cognition, and learning in children and adolescents [47-50]. In our study, both cereals and fruits (and fruit juices without added sugar) were not associated with significant cognitive performance differences. However, scientific literature has shown inconclusive results on this matter; for instance, some authors declare that eating cereal as part of the breakfast reduces attention deficit by more than a half, improving immediate word recall [13]. This favorable result has been associated with the breakfast's glycemic index; however, an experimental study showed improvements in cognitive tasks when adolescents consumed a high glycemic index breakfast [40]. Furthermore, a recent systematic review concluded that a favorable cognitive function is observed independently when having a low or high glycemic index breakfast [51].

On the other hand, fruit consumption has been associated with several beneficial health indicators, such as lower cardiovascular risk, cancer, chronic diseases, and illness [52]. The concentration of flavonoids and antioxidants in fruits have been shown to ameliorate cognitive impairment [53]; however, an experimental study in an animal model showed that fructose consumption reduces hippocampal synaptic plasticity, which underlies cognitive performance [54]. In particular, the protocol study by Cisternas et al. (2015) [54] induced metabolic syndrome in mice consuming fructose $(15 \%)$ and observed a significant reduction of the hippocampus to sustain synaptic plasticity (number of contact zones and the size of postsynaptic densities) and hippocampal neurogenesis after eight 
weeks. These findings were confirmed by Jiménez-Maldonado et al. (2018) [55], concluding that a short period of fructose consumption can affect brain plasticity without altering the peripheral metabolic dysfunction. In addition, recently, a theoretical article indicated that fructose can disrupt cerebral metabolism and neuronal function, leading to Alzheimer's disease [56]. Experimental and longitudinal studies in humans are necessary to understand how fructose can affect the human brain and cognitive functioning.

\subsubsection{Dairy Products}

Based on epidemiological and experimental studies, a reduced risk of obesity and cardiovascular disease was observed when people included dairy products (e.g., milk, yoghurt, cheese) in their daily diet [57]. Additionally, dairy in breakfast has an important role on improving growth and brain function in school-age children [16]; indeed, fortified milk could be an effective way to obtain polyunsaturated fatty acids, a crucial nutrient favouring brain development [58]. Furthermore, dairy products are rich in micronutrients, such as vitamins (C, D, B6, B12) and minerals (calcium, zinc, selenium) [5,59], all of which are relevant to the brain development and function [60]. Our findings support this conclusion, because adolescents who included dairy in breakfast had greater global cognitive performance results.

On the other side, few children and adolescents include dairy products in their breakfast due to socio-economic and educational factors [61,62]. For instance, a study in Spanish schoolchildren (9-13 years-old) found that $32 \%$ of girls and $17 \%$ of boys had a dairy product (e.g., milk, yoghurt) for breakfast [63]. In general, dairy products' consumption is low in diverse countries [62], challenging the dietary calcium recommendations associated with a diet deficient in several nutrients [64]. Finally, calcium consumption has been related to fat oxidation in adults $[57,65]$. Therefore, it is possible to speculate that dairy products could be deemed a mediator in the relationship between obesity and cognitive performance. Mediation and moderation studies are necessary to elucidate this and other research questions related to this crucial nutritional matter in adolescents' brain development.

\subsection{Future Studies, Strengths and Limitations}

Some questions emerged from the present findings that may complement this research area in future studies related to adolescents' cognitive performance, such as (a) the longterm effects of breakfast, (b) the relationship between diverse macro- and micronutrients, (c) the impact of breakfast in children and adolescents with poor nutritional status, and (d) the influence of socio-economic and vulnerability factors.

Finally, our study presented some limitations; for instance, the applied questionnaires did not assess for specific compositions of breakfast or the quantities of each food and nutrients consumed. Additionally, the assessment was done verbally, which is known to be biased. Furthermore, the cross-sectional design precluded the determination of causality, even with careful adjustment for covariates. Finally, the lack of a personal socioeconomic indicator must be considered. Nonetheless, our study had some strengths, such as the large sample size, the inclusion of different cognitive tasks to compute a global cognitive score, and the quality of potential confounders included in our analyses (i.e., a global physical fitness score). To our knowledge, this is the first study that evidences the relationship between breakfast consumption and cognitive performance in adolescents in Latin America.

\section{Conclusions}

Adolescents with a normal-BMIz and those with overweight/obesity had higher performance when having breakfast just before a cognitive evaluation and including at least two breakfast quality components, particularly, dairy products. Skipping breakfast regularly was negatively linked with lower cognitive performance, especially in adolescents living with overweight/obesity. These findings suggest that parents and children's nutritional education at school and on a public health level, regarding the importance 
of having breakfast, could be an influent strategy for improving cognitive performance. Intervention studies are needed to corroborate the present results.

Author Contributions: C.C.-M. contributed to the design of the project and is the corresponding author. C.C.-M., H.P.-J., and V.C.-N. conceptualized the design of the study. C.C.-M., H.P.-J., and V.C.-N. analyzed the data and wrote the concept version of the manuscript. K.P.S., G.F., and C.J.-A. critically reviewed the manuscript and edited the paper. All authors have given final approval of the manuscript and agreed to be accountable for the accuracy and integrity of any part of the work. All authors have read and agreed to the published version of the manuscript.

Funding: Cogni-Action Project was supported by the National Commission for Scientific and Technological Research CONICYT/FONDECYT INICIACION 2016 grant no. 11160703.

Institutional Review Board Statement: The study was conducted according to the guidelines of the Declaration of Helsinki and approved by the Bioethics and Biosafety Committee of the Pontificia Universidad Católica de Valparaíso (BIOEPUCV-H103-2016).

Informed Consent Statement: Informed consent was obtained from all subjects involved in the study.

Data Availability Statement: The data presented in this study are available on request from the corresponding author. The data are not publicly available due to ethical concerns.

Acknowledgments: We would like to acknowledge Paola Guerrero, Patricio Solis-Urra, Jorge Olivares-Arancibia, Javier Sanchez-Martinez, Tamara Huber-Perez, and all student assistants for gathering the data in the schools.

Conflicts of Interest: The authors declare no conflict of interest.

\section{References}

1. Dalwood, P.; Marshall, S.; Burrows, T.L.; McIntosh, A.; Collins, C.E. Diet quality indices and their associations with health-related outcomes in children and adolescents: An updated systematic review. Nutr. J. 2020, 19, 1-43. [CrossRef] [PubMed]

2. Reichelt, A.C.; Rank, M.M. The impact of junk foods on the adolescent brain. Birth Defects Res. 2017, 109, 1649-1658. [CrossRef] [PubMed]

3. Scaglioni, S.; De Cosmi, V.; Ciappolino, V.; Parazzini, F.; Brambilla, P.; Agostoni, C. Factors influencing children's eating behaviours. Nutrients 2018, 10, 706. [CrossRef] [PubMed]

4. O”Neil, C.E.; Nicklas, T.A. Breakfast Consumption versus Breakfast Skipping: The Effect on Nutrient Intake, Weight, and Cognition. In Nurturing a Healthy Generation of Children: Research Gaps and Opportunities; Karger Publishers: Basel, Switzerland, 2019; Volume 91, pp. 153-167. [CrossRef]

5. Giménez-Legarre, N.; Miguel-Berges, M.L.; Flores-Barrantes, P.; Santaliestra-Pasías, A.M.; Moreno, L.A. Breakfast characteristics and its association with daily micronutrients intake in children and adolescents-A systematic review and meta-analysis. Nutrients 2020, 12, 3201. [CrossRef] [PubMed]

6. Carneiro, L.; Leloup, C. Mens Sana in corpore Sano: Does the glycemic index have a role to play? Nutrients 2020, 12, 2989. [CrossRef]

7. Leidy, H.J.; Racki, E.M. The addition of a protein-rich breakfast and its effects on acute appetite control and food intake in breakfast-skipping adolescents. Int. J. Obes. 2010, 34, 1125-1133. [CrossRef]

8. Li, Y.; Dai, Q.; Jackson, J.C.; Zhang, J. Overweight is associated with decreased cognitive functioning among school-age children and adolescents. Obesity 2008, 16, 1809-1815. [CrossRef]

9. Meo, S.A.; Altuwaym, A.A.; Alfallaj, R.M.; Alduraibi, K.A.; Alhamoudi, A.M.; Alghamdi, S.M.; Akram, A. Effect of Obesity on Cognitive Function among School Adolescents: A Cross-Sectional Study. Obes. Facts 2019, 12, 150-156. [CrossRef]

10. Roberts, S.B.; Franceschini, M.A.; Silver, R.E.; Taylor, S.F.; De Sa, A.B.; Có, R.; Sonco, A.; Krauss, A.; Taetzsch, A.; Webb, P.; et al. Effects of food supplementation on cognitive function, cerebral blood flow, and nutritional status in young children at risk of undernutrition: Randomized controlled trial. BMJ 2020, 370. [CrossRef]

11. Lundqvist, M.; Vogel, N.E.; Levin, L.Å. Effects of eating breakfast on children and adolescents: A systematic review of potentially relevant outcomes in economic evaluations. Food Nutr. Res. 2019, 63. [CrossRef]

12. Yao, J.; Liu, Y.; Zhou, S. Effect of eating breakfast on cognitive development of elementary and middle school students: An empirical study using large-scale provincial survey data. Med. Sci. Monit. 2019, 25, 8843-8853. [CrossRef] [PubMed]

13. Wesnes, K.A.; Pincock, C.; Richardson, D.; Helm, G.; Hails, S. Breakfast reduces declines in attention and memory over the morning in schoolchildren. Appetite 2003, 41, 329-331. [CrossRef] [PubMed]

14. Wesnes, K.A.; Pincock, C.; Scholey, A. Breakfast is associated with enhanced cognitive function in schoolchildren. An internet based study. Appetite 2012, 59, 646-649. [CrossRef] [PubMed]

15. Maffeis, C.; Fornari, E.; Surano, M.G.; Comencini, E.; Corradi, M.; Tommasi, M.; Fasan, I.; Cortese, S. Breakfast skipping in prepubertal obese children: Hormonal, metabolic and cognitive consequences. Eur. J. Clin. Nutr. 2012, 66, 314-321. [CrossRef] 
16. Monzani, A.; Ricotti, R.; Caputo, M.; Solito, A.; Archero, F.; Bellone, S.; Prodam, F. A systematic review of the association of skipping breakfast with weight and cardiometabolic risk factors in children and adolescents. What should we better investigate in the future? Nutrients 2019, 11, 387. [CrossRef]

17. Rampersaud, G.C.; Pereira, M.A.; Girard, B.L.; Adams, J.; Metzl, J.D. Breakfast habits, nutritional status, body weight, and academic performance in children and adolescents. J. Am. Diet. Assoc. 2005, 105, 743-760. [CrossRef]

18. Barr, S.I.; DiFrancesco, L.; Fulgoni, V.L. Breakfast consumption is positively associated with nutrient adequacy in Canadian children and adolescents. Br. J. Nutr. 2014, 112, 1373-1383. [CrossRef]

19. Vereecken, C.; Dupuy, M.; Rasmussen, M.; Kelly, C.; Nansel, T.R.; Al Sabbah, H.; Baldassari, D.; Jordan, M.D.; Maes, L.; Niclasen, B.V.L.; et al. Breakfast consumption and its socio-demographic and lifestyle correlates in schoolchildren in 41 countries participating in the HBSC study. Int. J. Public Health 2009, 54, 180-190. [CrossRef]

20. Niemeier, H.M.; Raynor, H.A.; Lloyd-Richardson, E.E.; Rogers, M.L.; Wing, R.R. Fast Food Consumption and Breakfast Skipping: Predictors of Weight Gain from Adolescence to Adulthood in a Nationally Representative Sample. J. Adolesc. Health 2006, 39, 842-849. [CrossRef] [PubMed]

21. Walk, A.M.; Raine, L.B.; Kramer, A.F.; Cohen, N.J.; Hillman, C.H.; Khan, N.A. Adiposity is related to neuroelectric indices of motor response preparation in preadolescent children. Int. J. Psychophysiol. 2020, 147, 176-183. [CrossRef]

22. Kuzawa, C.W.; Blair, C. A hypothesis linking the energy demand of the brain to obesity risk. Proc. Natl. Acad. Sci. USA 2019, 116, 13266-13275. [CrossRef] [PubMed]

23. Dekkers, I.A.; Jansen, P.R.; Lamb, H.J. Erratum: Obesity, brain volume, and white matter microstructure at MRI: A cross-sectional UK biobank study. Radiology 2019, 291, 763-771. [CrossRef]

24. Cope, E.C.; Lamarca, E.A.; Monari, P.K.; Olson, L.B.; Martinez, S.; Zych, A.D.; Katchur, N.J.; Gould, E. Microglia play an active role in obesity-associated cognitive decline. J. Neurosci. 2018, 38, 8889-8904. [CrossRef] [PubMed]

25. Afzal, A.S.; Gortmaker, S. The relationship between obesity and cognitive performance in children: A longitudinal study. Child. Obes. 2015, 11, 466-474. [CrossRef]

26. Solis-Urra, P.; Olivares-Arancibia, J.; Suarez-Cadenas, E.; Sanchez-Martinez, J.; Rodríguez-Rodríguez, F.; Ortega, F.B.; EstebanCornejo, I.; Cadenas-Sanchez, C.; Castro-Piñero, J.; Veloz, A.; et al. Study protocol and rationale of the "cogni-action project" a cross-sectional and randomized controlled trial about physical activity, brain health, cognition, and educational achievement in schoolchildren. BMC Pediatr. 2019, 19, 1-16. [CrossRef]

27. Morrison, G.E.; Simone, C.M.; Ng, N.F.; Hardy, J.L. Reliability and validity of the NeuroCognitive Performance Test, a web-based neuropsychological assessment. Front. Psychol. 2015, 6, 1652. [CrossRef]

28. De Onis, M.; Onyango, A.W.; Borghi, E.; Siyam, A.; Nishida, C.; Siekmann, J. Development of a WHO growth reference for school-aged children and adolescents. Bull. World Health Organ. 2007, 85, 660-667. [CrossRef] [PubMed]

29. Serra-Majem, L.; Ribas, L.; Ngo, J.; Ortega, R.M.; García, A.; Pérez-Rodrigo, C.; Aranceta, J. Food, youth and the Mediterranean diet in Spain. Development of KIDMED, Mediterranean Diet Quality Index in children and adolescents. Public Health Nutr. 2004, 7, 931-935. [CrossRef]

30. Serra-Majem, L.; Ribas, L.; Pérez-Rodrigo, C.; García-Closas, R.; Peña-Quintana, L.; Aranceta, J. Determinants of nutrient intake among children and adolescents: Results from the enKid study. Ann. Nutr. Metab. 2002, 46, 31-38. [CrossRef]

31. Laube, C.; van den Bos, W.; Fandakova, Y. The relationship between pubertal hormones and brain plasticity: Implications for cognitive training in adolescence. Dev. Cogn. Neurosci. 2020, 42, 100753. [CrossRef]

32. Moore, S.A.; McKay, H.A.; Macdonald, H.; Nettlefold, L.; Baxter-Jones, A.D.G.; Cameron, N.; Brasher, P.M.A. Enhancing a somatic maturity prediction model. Med. Sci. Sports Exerc. 2015, 47, 1755-1764. [CrossRef] [PubMed]

33. Ruiz, J.R.; Castro-Pinero, J.; Espana-Romero, V.; Artero, E.G.; Ortega, F.B.; Cuenca, M.M.; Jimenez-Pavon, D.; Chillon, P.; GirelaRejon, M.J.; Mora, J.; et al. Field-based fitness assessment in young people: The ALPHA health-related fitness test battery for children and adolescents. Br. J. Sports Med. 2011, 45, 518-524. [CrossRef]

34. Schwab, J.F.; Lew-Williams, C. Language learning, socio-economic status, and child-directed speech. Wiley Interdiscip. Rev. Cogn. Sci. 2016, 7, 264-275. [CrossRef] [PubMed]

35. Duarte, J.; Bos, M.S.; Moreno, M. Inequity in School Achievement in Latin America. Multilevel Analysis of SERCE Results According to the Socioeconomic Status of Students; IADB: New York, NY, USA, 2010.

36. Mazzoni, C.C.; Stelzer, F.; Cervigni, M.A.; Martino, P. Impacto de la pobreza en el desarrollo cognitivo: Un análisis teórico de dos factores mediadores. Liberabit 2014, 20, 93-100.

37. Lumley, T.; Diehr, P.; Emerson, S.; Chen, L. The importance of the normality assumption in large public health data sets. Annu. Rev. Public Health 2002, 23, 151-169. [CrossRef]

38. Cohen, J. Statistical Power Analysis for the Behavioral Sciences. Google Libros. Available online: https://books. google.cl/books?hl=es\&lr=\&id=rEe0BQAAQBAJ\&oi=fnd\&pg=PP1\&dq=37.+Cohen+J.+Statistical+power+analysis +for + the+behavioral+sciences.+Lawrence+Erlbaum+Associates, + Hillsdale,+NJ.1988\&ots=swTZJvNQp5\&sig=HUcCDrWJhz4 HEFt6WMCseHIVOqo\#v=onepage\&q\&f=false (accessed on 28 December 2020).

39. Betts, J.A.; Chowdhury, E.A.; Gonzalez, J.T.; Richardson, J.D.; Tsintzas, K.; Thompson, D. Is breakfast the most important meal of the day? Proc. Nutr. Soc. 2016, 75, 464. [CrossRef]

40. Zilberter, T.; Zilberter, E.Y. Breakfast and cognition: Sixteen effects in nine populations, no single recipe. Front. Hum. Neurosci. 2013, 7, 631. [CrossRef] 
41. Sievert, K.; Hussain, S.M.; Page, M.J.; Wang, Y.; Hughes, H.J.; Malek, M.; Cicuttini, F.M. Effect of breakfast on weight and energy intake: Systematic review and meta-analysis of randomised controlled trials. BMJ 2019, 364, 142. [CrossRef]

42. Pollitt, E.; Lewis, N.L.; Garza, C.; Shulman, R.J. Fasting and cognitive function. J. Psychiatr. Res. 1982, 17, 169-174. [CrossRef]

43. Kral, T.V.E.; Heo, M.; Whiteford, L.M.; Faith, M.S. Effects on cognitive performance of eating compared with omitting breakfast in elementary schoolchildren. J. Dev. Behav. Pediatr. 2012, 33, 9-16. [CrossRef]

44. Paz-Filho, G.J.; Babikian, T.; Asarnow, R.; Esposito, K.; Erol, H.K.; Wong, M.L.; Licinio, J. Leptin Replacement Improves Cognitive Development. PLoS ONE 2008, 3, e3098. [CrossRef]

45. Moore, G.F.; Tapper, K.; Murphy, S.; Lynch, R.; Raisanen, L.; Pimm, C.; Moore, L. Associations between deprivation, attitudes towards eating breakfast and breakfast eating behaviours in 9-11-year-olds. Public Health Nutr. 2007, 10, 582-589. [CrossRef]

46. Schneider, S.; Diehl, K.; Görig, T.; Schilling, L.; De Bock, F.; Hoffmann, K.; Albrecht, M.; Sonntag, D.; Fischer, J. Contextual influences on physical activity and eating habits-options for action on the community level. BMC Public Health 2017, 17, 760. [CrossRef] [PubMed]

47. Adolphus, K.; Lawton, C.L.; Dye, L. The effects of breakfast on behaviour and academic performance in children and adolescents. Front. Hum. Neurosci. 2013, 7, 425. [CrossRef] [PubMed]

48. Adolphus, K.; Bellissimo, N.; Lawton, C.L.; Ford, N.A.; Rains, T.M.; de Zepetnek, J.T.; Dye, L. Methodological challenges in studies examining the effects of breakfast on cognitive performance and appetite in children and adolescents. Adv. Nutr. 2017, 8, 184S-196S. [CrossRef] [PubMed]

49. Sámano, R.; Hernández-Chávez, C.; Chico-Barba, G.; Córdova-Barrios, A.; Morales-Del-olmo, M.; Sordo-Figuero, H.; Hernández, M.; Merino-Palacios, C.; Cervantes-Zamora, L.; Martínez-Rojano, H. Breakfast nutritional quality and cognitive interference in university students from Mexico city. Int. J. Environ. Res. Public Health 2019, 16, 2671. [CrossRef] [PubMed]

50. Micha, R.; Rogers, P.J.; Nelson, M. Glycaemic index and glycaemic load of breakfast predict cognitive function and mood in school children: A randomised controlled trial. Br. J. Nutr. 2011, 106, 1552-1561. [CrossRef] [PubMed]

51. Álvarez-Bueno, C.; Martínez-Vizcaíno, V.; López, E.J.; Visier-Alfonso, M.E.; Redondo-Tébar, A.; Cavero-Redondo, I. Comparative effect of low-glycemic index versus high-glycemic index breakfasts on cognitive function: A systematic review and meta-analysis. Nutrients 2019, 11, 1706. [CrossRef] [PubMed]

52. Carrillo, J.Á.; Pilar Zafrilla, M.; Marhuenda, J. Cognitive function and consumption of fruit and vegetable polyphenols in a young population: Is there a relationship? Foods 2019, 8, 507. [CrossRef]

53. Bleiweiss-Sande, R.; Chui, K.; Wright, C.; Amin, S.; Anzman-Frasca, S.; Sacheck, J.M. Associations between food group intake, cognition, and academic achievement in elementary schoolchildren. Nutrients 2019, 11, 2722. [CrossRef]

54. Cisternas, P.; Salazar, P.; Serrano, F.G.; Montecinos-Oliva, C.; Arredondo, S.B.; Varela-Nallar, L.; Barja, S.; Vio, C.P.; Gomez-Pinilla, F.; Inestrosa, N.C. Fructose consumption reduces hippocampal synaptic plasticity underlying cognitive performance. Biochim. Biophys. Acta (BBA) Mol. Basis Dis. 2015, 1852, 2379-2390. [CrossRef] [PubMed]

55. Jiménez-Maldonado, A.; Ying, Z.; Byun, H.R.; Gomez-Pinilla, F. Short-term fructose ingestion affects the brain independently from establishment of metabolic syndrome. Biochim. Biophys. Acta (BBA) Mol. Basis Dis. 2018, 1864, 24-33. [CrossRef]

56. Johnson, R.J.; Gomez-Pinilla, F.; Nagel, M.; Nakagawa, T.; Rodriguez-Iturbe, B.; Sanchez-Lozada, L.G.; Tolan, D.R.; Lanaspa, M.A. Cerebral Fructose Metabolism as a Potential Mechanism Driving Alzheimer's Disease. Front. Aging Neurosci. $2020,12,11$. [CrossRef]

57. Astrup, A. Yogurt and dairy product consumption to prevent cardiometabolic diseases: Epidemiologic and experimental studies. Am. J. Clin. Nutr. 2014, 99, 1235S-1242S. [CrossRef]

58. Petrova, D.; Bernabeu Litrán, M.A.; García-Mármol, E.; Rodríguez-Rodríguez, M.; Cueto-Martín, B.; López-Huertas, E.; Catena, A.; Fonollá, J. Effects of fortified milk on cognitive abilities in school-aged children: Results from a randomized-controlled trial. Eur. J. Nutr. 2019, 58, 1863-1872. [CrossRef]

59. Gaucheron, F. Milk and dairy products: A unique micronutrient combination. J. Am. Coll. Nutr. 2011, 30, 400S-409S. [CrossRef]

60. Gómez-Pinilla, F. Brain foods: The effects of nutrients on brain function. Nat. Rev. Neurosci. 2008, 9, 568-578. [CrossRef]

61. Possa, G.; Corrente, J.E.; Fisberg, M. Yogurt consumption is associated with a better lifestyle in Brazilian population. BMC Nutr. 2017, 3, 29. [CrossRef]

62. Guiné, R.P.F.; Florença, S.G.; Carpes, S.; Anjos, O. Study of the Influence of Sociodemographic and Lifestyle Factors on Consumption of Dairy Products: Preliminary Study in Portugal and Brazil. Foods 2020, 9, 1775. [CrossRef] [PubMed]

63. Ortega, R.M.; Requejo, A.M.; Redondo, R.; López-Sobaler, A.M.; Andrés, P.; Ortega, A.; Gaspar, M.J.; Quintas, E.; Navia, B. Influence of the Intake of Fortified Breakfast Cereals on Dietary Habits and Nutritional Status of Spanish Schoolchildren. Ann. Nutr. Metab. 1996, 40, 146-156. [CrossRef]

64. Rafferty, K.; Watson, P.; Lappe, J.M. The Selection and Prevalence of Natural and Fortified Calcium Food Sources in the Diets of Adolescent Girls. J. Nutr. Educ. Behav. 2011, 43, 96-102. [CrossRef]

65. Gonzalez, J.T.; Rumbold, P.L.S.; Stevenson, E.J. Effect of calcium intake on fat oxidation in adults: A meta-analysis of randomised, controlled trials. Obes. Rev. 2012, 13, 848-857. [CrossRef] [PubMed] 